\title{
Erratum
}

\section{Erratum to "Fundamental Solutions to Kolmogorov Equations via Reduction to Canonical Form"}

\section{Joanna Goard}

School of Mathematics and Applied Statistics, University of Wollongong, Wollongong, NSW 2522, Australia

Correspondence should be addressed to Joanna Goard, joanna@uow.edu.au

Received 23 June 2011; Accepted 3 July 2011

Copyright (c) 2011 Joanna Goard. This is an open access article distributed under the Creative Commons Attribution License, which permits unrestricted use, distribution, and reproduction in any medium, provided the original work is properly cited.

The original paper was published in the Journal of Applied Mathematics and Decision Sciences, volume 2006, Article ID 19181, pp. 1-24.

There is a constant 2 missing in the denominator of the second exponential term in (3.9). The equation should read that for $r \geq 0, \gamma \neq 1$, we can write

$$
\begin{aligned}
p\left(x, t ; y, t^{\prime}\right)= & \frac{x^{1 / 2} y^{1 / 2-2 \gamma}}{c^{2}|1-\gamma|\left(t^{\prime}-t\right)} \exp \left\{\frac{k_{2}}{2}\left(t^{\prime}-t\right)\right\} \exp \left\{-\frac{\left(x^{2-2 \gamma}+y^{2-2 \gamma}\right)}{2 c^{2}(1-\gamma)^{2}\left(t^{\prime}-t\right)}\right\} \\
& \times I_{\nu}\left(\frac{y^{1-\gamma} x^{1-\gamma}}{c^{2}(1-\gamma)^{2}\left(t^{\prime}-t\right)}\right) \exp \left\{\frac{1}{c^{2}} \int^{y} \frac{A(x)}{x^{2 \gamma}} d x-\frac{1}{c^{2}} \int^{x} \frac{A(x)}{x^{2 \gamma}} d x\right\} .
\end{aligned}
$$




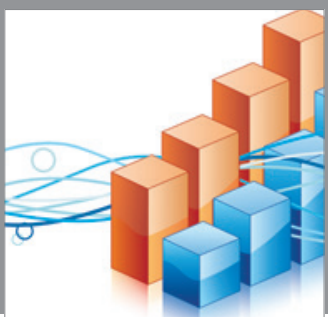

Advances in

Operations Research

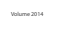

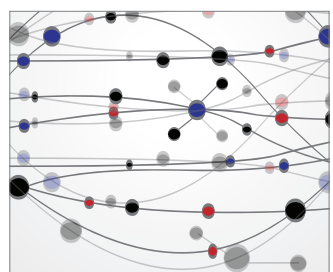

\section{The Scientific} World Journal
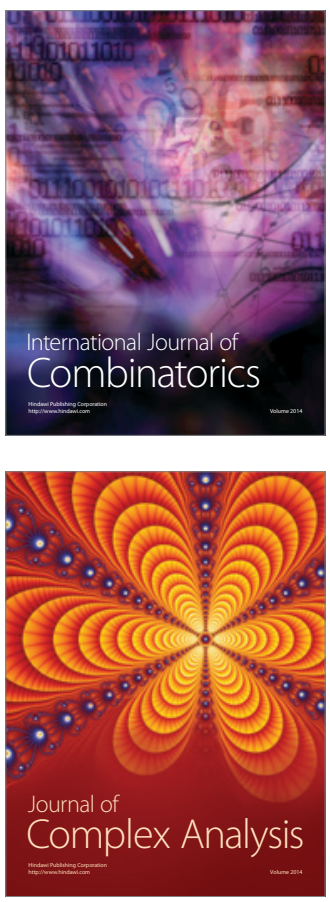

International Journal of

Mathematics and

Mathematical

Sciences
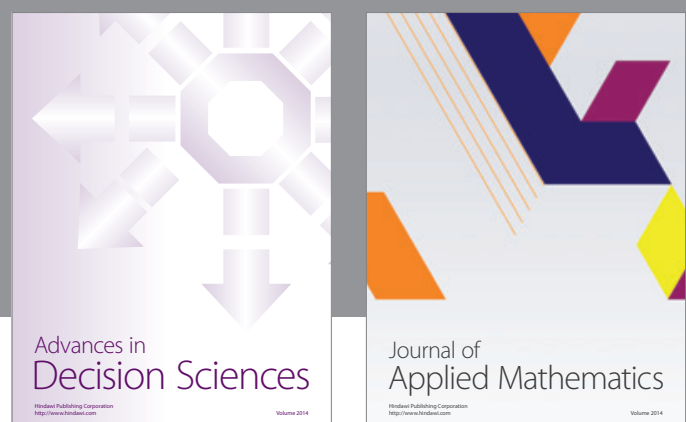

Journal of

Applied Mathematics
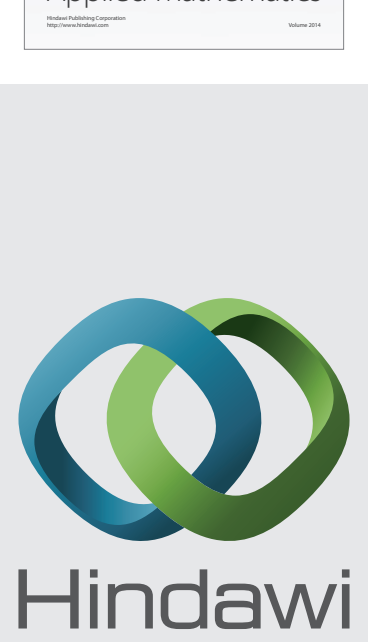

Submit your manuscripts at http://www.hindawi.com
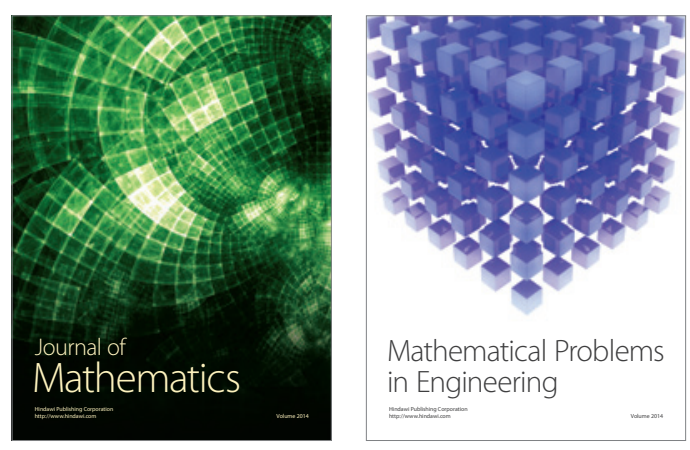

Mathematical Problems in Engineering
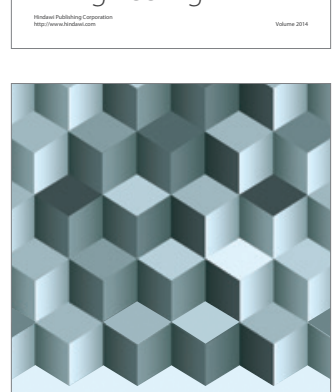

Journal of

Function Spaces
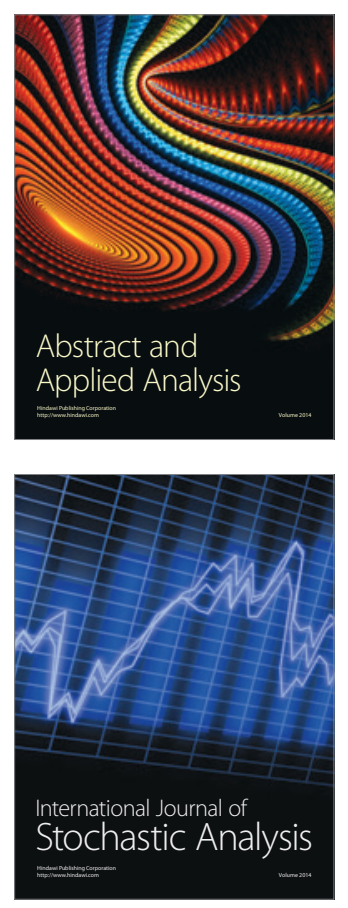

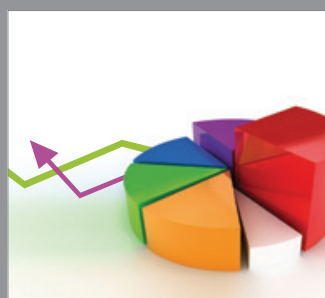

ournal of

Probability and Statistics

Promensencen
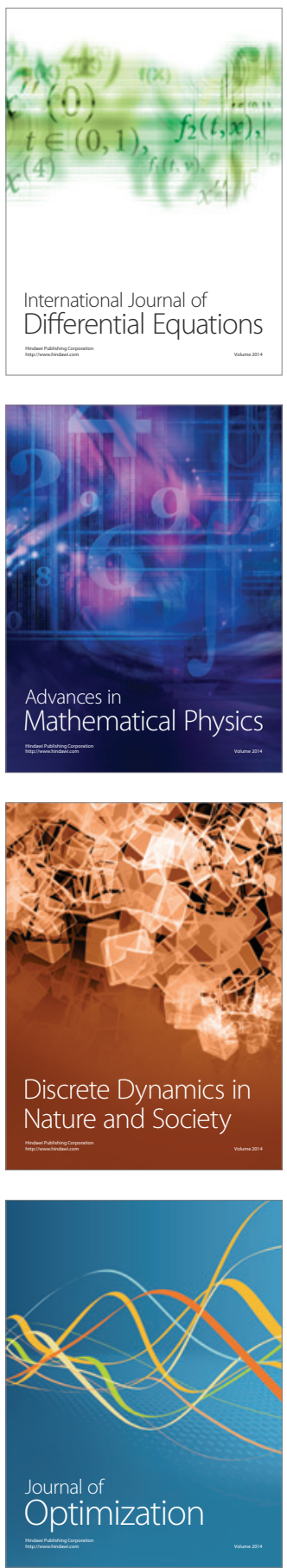